\title{
A comparative study of laparoscopic assisted vaginal hysterectomy versus total abdominal hysterectomy in benign gynaecological conditions
}

\author{
Pandala Sravanthi $^{1 *}$, D. Shivani², Naga Jyothi Gunturu ${ }^{3}$
}

\begin{abstract}
${ }^{1}$ Department of Obstetrics and Gynaecology, NRI Academy of Medical Sciences, Mangalagiri Road, Chinakakani, Guntur, Andhra Pradesh, India

${ }^{2}$ Department of Obstetrics and Gynaecology, Preethi Nursing Home, Guntakal, Andhra Pradesh, India

${ }^{3}$ Department of Obstetrics and Gynaecology, Narayana Superspeciality Hospital, Kothapeta, Guntur, Andhra Pradesh, India
\end{abstract}

Received: 26 January 2021

Revised: 05 March 2021

Accepted: 06 March 2021

\section{*Correspondence:}

Dr. Pandala Sravanthi,

E-mail: research.nmch@rediffmail.com

Copyright: (c) the author(s), publisher and licensee Medip Academy. This is an open-access article distributed under the terms of the Creative Commons Attribution Non-Commercial License, which permits unrestricted non-commercial use, distribution, and reproduction in any medium, provided the original work is properly cited.

\begin{abstract}
Background: Laparoscopic assisted vaginal hysterectomy (LAVH) has become an alternative to Total Abdominal Hysterectomy $(\mathrm{TAH})$ in cases difficult to manage via vaginal route. To compare the TAH and LAVH for benign uterine pathology.

Methods: This prospective study conducted with the outcomes of Laparoscopic assisted vaginal hysterectomy with Total abdominal hysterectomy over a period of 2 years in 100 patients who are undergoing hysterectomies for benign uterine pathology. 50 underwent TAH and 50 underwent Laparoscopic Assisted Vaginal hysterectomy.

Results: The average duration of surgery in TAH group is 50 minutes and it is 75 minutes in LAVH group $(p<0.05)$. In TAH group, blood loss was more $(250-500 \mathrm{ml})$ in $28 \%$ of patients, where as it was $<250 \mathrm{ml}$ in $92 \%$ of patients in LAVH group. Mean blood loss is $238 \mathrm{ml}$ and $130 \mathrm{ml}$ in TAH and LAVH group (p<0.01). Only $3(6 \%)$ patients in LAVH group required blood transfusion $(\mathrm{p}>0.05)$. Recovery and return to work after discharge from hospital was early with LAVH group as early as 2 weeks in $46 \%$ of patients. In TAH group, it was late by 4 weeks in $52 \%$ of patients and by 6 weeks in $10 \%$ of patients.

Conclusions: Thus, it can be concluded that LAVH is safe with less blood loss, shorter duration of hospital stay, early recovery to work, and other intra-operative and post-operative complications.
\end{abstract}

Keywords: Blood transfusion, Hysterectomy, Laparoscopic, Uterine pathology

\section{INTRODUCTION}

Hysterectomy is defined as the removal of the uterus. ${ }^{1}$ Hysterectomy is the most often indicated when medical treatment or minimally invasive procedures have failed.

Hysterectomy performed abdominally, vaginally, or through abdominal ports with the assist of a laparoscope. Total abdominal hysterectomy was first described in
1878 by Freund $1878 .^{2}$ The TAH technique was introduced by Richardsson $1929 .{ }^{3}$ He advocated the total procedure to prevent cervical stump carcinoma development.

Since Harry Reich described Laparoscopic hysterectomy surgery in 1989, laparoscopic-assisted vaginal hysterectomy (LAVH) became the popular alternative to abdominal hysterectomy cases difficult by vaginal route. ${ }^{4}$ 
Within the past decade, the acceptance of minimally invasive techniques changed the traditional approach to hysterectomy from open abdominal surgery to laparoscopy.

The idea of LAVH is to convert a potential abdominal hysterectomy to a vaginal one, thus decreasing associated morbidity and hastening recovery. Moreover, the LAVH technique is further developed, and variations relate mainly to the dissection of major vessels and the cardinal ligaments where bipolar cautery, stapling devices, and/or extra- or intracorporeal sutures may be used. Laparoscopy offers a superior tissue image of the abdominopelvic cavity, facilitates meticulous hemostasis, and reduces laparotomy morbidity. ACOG acknowledges the choice of the surgical indication, the patient's condition, and data and the surgeon's expertise. This study allows the comparison of Total Abdominal Hysterectomy (TAH), and Laparoscopic Assisted Vaginal Hysterectomy (LAVH) for benign uterine pathology.

\section{METHODS}

A Prospective Study conducted on 100 patients undergoing hysterectomy for benign uterine pathology meeting the inclusion and exclusion criterion will be included in the study. The study period is from October 2015 to October 2017 at Narayana Medical College and Hospital, Nellore.

One hundred patients undergoing hysterectomy for benign gynecological conditions. 50-Laparoscopic assisted vaginal hysterectomy and 50-Total abdominal hysterectomy.

Inclusion criteria are All women undergoing hysterectomy for benign Uterine pathology, Uterine size not exceeding 14 weeks size, No contraindications for gas insufflations, No extensive adhesions in pelvis, No cardiac or pulmonary diseases, and no contraindications to Lithotomy position.

Exclusion Criteria are Woman with Uterine size>14 weeks size, Woman with associated Ovarian mass, Woman with associated Pelvic inflammatory disease, Uterine descent-2nd and 3rd degree, and genital malignancy. All women undergoing hysterectomy meeting the inclusion criteria will be divided into 2 groups - LAVH group and TAH group.

\section{Outcome}

Type of anesthesia Time of surgery, Operative- Blood loss, Injuries- bladder, ureter, bowel Post-operative Vitals. Operative intervention includes Time of surgery, Blood loss estimation, Intra op injuries. Post-operative Evaluation include vitals measured at least two times a day, Pain scoring (visual analogue scale \& analgesics consumed) Day of ambulation post-operatively, Postoperative complications, Hospital stay, Follow up after 2wks. Statistical analysis performed using SPSS Version 18. Descriptive statistics scu as mean, standard deviation, and range were calculated for all the important parameters recorded in this study. Quantitative variables like have been described as mean and standard deviation. Qualitative variables have been described in the form of percentages. Analysis of significance performed t test, and chi square test. A p value 0.05 or less has been considered as statistically significant.

\section{RESULTS}

$96 \%$ of women of TAH group needed spinal anesthesia and only $4 \%$ needed general anesthesia. On the other hand all the women of LAVH group needed general anesthesia $(\mathrm{P}<0.05)$. Duration of surgery was little more in patients who underwent LAVH when compared to patients who underwent TAH. The average duration of surgery in TAH group is 50 minutes and it is 75 minutes in LAVH group $(\mathrm{P}<0.05)$. In TAH group, blood loss was more $(250-500 \mathrm{ml})$ in $28 \%$ of patients, where as it was $<250 \mathrm{ml}$ in $92 \%$ of patients in LAVH group. Average blood loss is $238 \mathrm{ml}$ and $130 \mathrm{ml}$ in TAH and LAVH group respectively $(\mathrm{P}<0.01)$. Only two patients $(4 \%)$ in TAH group had bladder injury where as in LAVH group one patient $(2 \%)$ had bladder injury and one patient $(2 \%)$ had bowel injury. No bowel and ureteric injuries in TAH group $(p>0.05)$. Only two patients in LAVH group needed conversion into laparotomy because of adhesions and uncontrollable hemorrhage. In LAVH group of patients, postoperatively, pain was less and there was no requirement of additional analgesia. The patients in TAH group complained of pain even on 3rd-5th postoperative day and required additional analgesia and hence mobilization was late in TAH group $(\mathrm{P}<0.05)$. Postoperative Ambulation was earlier in patients who underwent LAVH due to less postoperative pain, where as it was late in patients of TAH group $(\mathrm{P}<0.05)$.

In $\mathrm{TAH}$ group, $18 \%$ of patients required blood transfusion because of significant intraoperative blood loss. Only $3(6 \%)$ patients in LAVH group required blood transfusion $(\mathrm{P}>0.05)$. Fever $(12 \%)$ and wound infection (12\%) was higher in TAH group than LAVH group $4 \%$ and $2 \%$. UTI (8\%) was also comparatively more in TAH group, which was the reason for longer hospital stay in TAH group. RTI was observed in 2 patients of LAVH group. Number of days in hospital was less in LAVH group 2-5 days in $82 \%$ patients because of less post op complications, pain and need for blood transfusion. LAVH group patients ambulated earlier and hence got discharged early.

Whereas TAH group patients had little longer stay 6-10 days in $82 \%$ patients because of wound infection and pain in postoperative period. Recovery and return to work after discharge from hospital was early with LAVH group as early as 2 weeks in $46 \%$ of patients. In TAH group it was late by 4 weeks in $52 \%$ of patients and by 6 weeks in $10 \%$ of patients. 
Table 1: Comparison of LAVH and TAH groups.

\begin{tabular}{|c|c|c|c|c|}
\hline & \multicolumn{2}{|c|}{$\begin{array}{l}\text { TAH } \\
\text { No. } \%\end{array}$} & \multicolumn{2}{|c|}{$\begin{array}{l}\text { LAVH } \\
\text { No. } \%\end{array}$} \\
\hline & $\mathbf{N}$ & $\%$ & $\mathbf{N}$ & $\%$ \\
\hline \multicolumn{5}{|l|}{ Type of Anaesthesia } \\
\hline Spinal & 48 & 96 & 0 & 0 \\
\hline G/A & 2 & 4 & 50 & 100 \\
\hline \multicolumn{5}{|l|}{ Duration of surgery } \\
\hline$<35$ & 4 & 8 & 0 & 0 \\
\hline $35-60$ & 28 & 56 & 23 & 46 \\
\hline $60-90$ & 16 & 32 & 22 & 44 \\
\hline $90-120$ & 2 & 4 & 5 & 10 \\
\hline \multicolumn{5}{|l|}{ Blood Loss (ml) } \\
\hline$<250$ & 33 & 66 & 46 & 92 \\
\hline $250-500$ & 14 & 28 & 4 & 8 \\
\hline$>500$ & 3 & 6 & 0 & 0 \\
\hline \multicolumn{5}{|c|}{ Intraoperative complications } \\
\hline Bowel injury & 0 & 0 & 1 & 2 \\
\hline Bladder injury & 2 & 4 & 1 & 2 \\
\hline Ureteric injury & 0 & 0 & 0 & 0 \\
\hline \multicolumn{5}{|l|}{ Laparotomy } \\
\hline No & 50 & 100.0 & 48 & 96.0 \\
\hline Yes & 0 & 0.0 & 2 & 4.0 \\
\hline \multicolumn{5}{|l|}{ Pain scale on day 3} \\
\hline 2 to 5 & 12 & 24.0 & 48 & 96.0 \\
\hline 6 to 10 & 38 & 76.0 & 2 & 4.0 \\
\hline \multicolumn{5}{|l|}{ Blood Transfusion } \\
\hline No & 41 & 82.0 & 47 & 94.0 \\
\hline Yes & 9 & 18.0 & 3 & 6.0 \\
\hline \multicolumn{5}{|l|}{$\begin{array}{l}\text { Post op } \\
\text { Complications }\end{array}$} \\
\hline Fever & 6 & 12 & 2 & 4 \\
\hline Wound Infection & 6 & 12 & 1 & 2 \\
\hline Bowel disturbances & 0 & 0 & 0 & 0 \\
\hline UTI & 4 & 8 & 2 & 4 \\
\hline RTI & 1 & 2 & 2 & 4 \\
\hline \multicolumn{5}{|l|}{ Hospital stay (days) } \\
\hline 1 to 2 & 0 & 0.0 & 0 & 0.0 \\
\hline 2 to 5 & 0 & 0.0 & 41 & 82.0 \\
\hline 6 to 10 & 41 & 82.0 & 9 & 18.0 \\
\hline$>10$ & 9 & 18.0 & 0 & 0.0 \\
\hline \multicolumn{5}{|l|}{$\begin{array}{l}\text { Return to work } \\
\text { (weeks) }\end{array}$} \\
\hline 1 & 0 & 0.0 & 2 & 4.0 \\
\hline 2 & 2 & 4.0 & 23 & 46.0 \\
\hline 3 & 10 & 20.0 & 21 & 42.0 \\
\hline 4 & 26 & 52.0 & 3 & 6.0 \\
\hline 5 & 7 & 14.0 & 1 & 2.0 \\
\hline 6 & 5 & 10.0 & 0 & 0.0 \\
\hline
\end{tabular}

\section{DISCUSSION}

In the present study it has been noted that, among the patients who underwent $\mathrm{TAH}$, spinal anaesthesia was given to $96 \%$ of patients and remaining $4 \%$ of patients were given general anaesthesia. Among the patients who underwent LAVH, all patients (100\%) were given general anaesthesia. In the study by Zesmin et al, it has been noted that $88 \%$ of patients who underwent TAH were given spinal anaesthesia and all the patients $(100 \%)$ who underwent $\mathrm{LAVH}$ received general anaesthesia. ${ }^{5}$

The present study inferred that only $4 \%$ of patients who underwent $\mathrm{TAH}$ needed general anesthesia because of dense adhesions which lead to extended operative time.

Duration of Surgery in our study was taken from the first surgical incision to the time when the last skin suture was applied in TAH and skin incision to vaginal dressing in LAVH.

Though there are many factors influencing the duration of hysterectomy, the two most important ones are mode of hysterectomy and the expertise of the surgeon. In our study in majority patients the operating time for TAH was 35-60 mins and for LAVH was 60-90 mins.

Blood loss during the laparoscopic phase in LAVH was calculated as the difference between the volume of fluid aspirated and that of the fluid introduced into the pelvic cavity. Blood loss during the vaginal phase of LAVH or during abdominal hysterectomy was determined directly from the aspirated fluid collected in the calibrated container.

Sponges used for mopping were also taken into consideration and one fully soaked sponge was calculated as $50 \mathrm{ml}$ of blood loss.

Upon studying outcome of surgery in relation to blood loss in the present study, it is noted that, intra operative blood loss was more in TAH group (250- $500 \mathrm{ml})$ when compared to intra operative blood loss in LAVH group (< $250 \mathrm{ml})$.

Lal Manju et al. ${ }^{6}$ ( TAH -125 to $175 \mathrm{ml}$, LAVH- 100 to $130 \mathrm{ml}$ ), Prasong et al. ${ }^{7}$ (TAH- 60 to $400 \mathrm{ml}$, LAVH- 40 to $250 \mathrm{ml}$ ), Kapoor Nisha et al. ${ }^{8}$ (TAH-150 ml, LAVH$116 \mathrm{ml}$ ), Kongwattanakul et al. ${ }^{9}$ (TAH- $250 \mathrm{ml}$, LAVH$120 \mathrm{ml})$.

In other two studies, intra operative blood loss was more with LAVH group when compared to TAH group, Ottosen et al. ${ }^{10}$ (TAH- 25 to $800 \mathrm{ml}$, LAVH -50 to 1400 $\mathrm{ml}$ ), Jyotsna et al (TAH- 200 to $300 \mathrm{ml}$, LAVH- 450-600 $\mathrm{ml})$.

Intra operative injuries were more in patients who underwent TAH when compared to patients who underwent LAVH. In our study, 2 patients had bladder injury in TAH group which occurred during the dissection of the bladder off the cervix and vagina because of dense adhesions. In LAVH group, 1 patient had bladder injury due to thick adhesions, which was converted to laparotomy and managed accordingly. The 
present study was supported by Kapoor $\mathrm{N}$ et al. ${ }^{8}$ study, which noticed injury to the bladder in 3 patients of TAH group because of previous cesarean section (LSCS) and one thermal ureteric injury. There was 1 bladder injury in Prasong et al. study. In our present study, in 2 patients of LAVH group there was conversion to laparotomy.

In one patient there were dense adhesions and bladder injury requiring conversion to laparotomy. In another patient, the laparoscopic procedure needed to be abandoned because of brisk, uncontrollable hemorrhage and finally the operation was completed by laparotomy.

In Ottosen et al. study, there was conversion to laparotomy in 4 patients of LAVH group because of dense adhesions in two cases, large uterus in one and excessive bleeding in the other. In Kapoor Nisha et al. study, 2 patients of LAVH group needed conversion to laparotomy- because of dense adhesions with the bowel. In the post-operative period, the pain was assessed either by Visual Analogue Scale or by estimating the amount of analgesics $(\mathrm{mg})$ required for pain relief. In the present study, significant difference was observed in patients between TAH and LAVH group in terms of pain (VAS) on $3^{\text {rd }}$ post-operative day. VAS was 6-10 in majority of patients who underwent $\mathrm{TAH}$, whereas it was less 2-5 in patients of LAVH group.

The present study was supported by Lal Manju et $\mathrm{al}^{6}$, Prasong et al, Zesmin et al. ${ }^{5}$ These studies had concluded that there was less need of analgesics in LAVH group when compared to TAH group. Intraoperative blood loss was more in TAH group than in LAVH group. The present study concludes that the post-operative blood transfusions were required in 9 patients who underwent TAH when compared to requirement of transfusion in 3 patients of LAVH group. During the postoperative phase, the need of blood transfusions was determined by intraoperative hemorrhage and mean drop of hemoglobin level on $3^{\text {rd }}$ postoperative day.

No significant difference was noted in terms of blood transfusion in the above mentioned studies, Lal Manju et al, Ottosen et al, Prasong et al, Zesmin et al.

In our present study, it is found that most common complication is fever followed by wound infection. Other complications being UTI and RTI. Fever observed in TAH group could be a manifestation of wound infection and UTI. Fever seen in LAVH group of patients following general anaesthesia is mostly due to wound infection and could be a manifestation of upper respiratory tract infection following intubation. Urinary tract infection following TAH could be due to prolonged catheterization. This is subsidized by the fact that there were less UTI following LAVH as stated in the study by JD Arbogast. ${ }^{11}$ The present study is in agreement with study by Arbogast, et al. and many others have documented UTI after TAH at more or less the same incidence.
Sutasanasuang S, et al. and J. D. Arbogast documented equal incidence of wound infection in LAVH and TAH cases. ${ }^{12}$ But most other studies have stated that wound infection following LAVH is nil. All post-operative complications were managed conservatively. It is observed that complications were more common with TAH group than LAVH group. Lal Manju et al and Jyotsna et al study support the present study. This was the reason for longer hospital stay in TAH group. It is observed that duration of hospital stay was more in patients of TAH group (6-10 days) as compared to LAVH group (2-5 days). Shorter hospital stay in patients of LAVH group seen in this study has also been supported by earlier studies, Jyotsna et al, Kapoor Nisha et al, Lal Manju et al, Prasong et al and Nambiar KPM et al. ${ }^{13,14}$

In LAVH group patients, duration of hospital stay was less because of less postoperative pain, complications and early ambulation. In the present study, return to normal activities was significantly quicker ( 2 weeks) in patients of LAVH group compared as to patients of TAH group. It took little longer time to return to work (4 weeks) in patients of TAH group. Time to return to work was significantly shortened among LAVH group as supported by all the above mentioned studies. In Prasong et al. study, he used a recovery scale of 1 to 10 . It showed significant difference in recovery score between LAVH and TAH groups as early as day 7 . This was more pronounced by day 14, when the mean scores for the LAVH group were 8 and 5 for the TAH group; significant differences even persisted to day 28, with scores of 9 and 7. Limitations of the study are study consists small sample size and single centre study.

\section{CONCLUSION}

LAVH is associated with less blood loss and decreased intra operative complications when compared to TAH. Length of hospital stay is significantly less for LAVH when compared to TAH. Ambulation and recovery to work are significantly earlier with LAVH. Cost for the LAVH is significantly higher than TAH. Post-operative pain, complications and blood transfusions are more with TAH group, because of which patient had longer hospital stay and took longer time for recovery and return to work. Thus it can be concluded that LAVH is safe with less blood loss, shorter duration of hospital stay, early recovery to work and other intra-operative and postoperative complications.

\section{Funding: No funding sources Conflict of interest: None declared \\ Ethical approval: The study was approved by the Institutional Ethics Committee}

\section{REFERENCES}

1. Robert S Kavoc. Guidelines to determine the route of hysterectomy.Obstet and Gynecol.1995;85(1):18-22. 
2. Freund W. Eine neue Methode der Extirpation des ganzen uterus. Samml Klin Vortr Gynäk 1878;41:911-24.

3. Richardson EH. A simplified technique for abdominal panhysterectomy. Surg Gynecol Obstet. 1929;48:248-51.

4. Reich H, DeCaprio J, McGlynn F. Laparoscopic hysterectomy. J Gynecol Surg. 1989;5:213-6.

5. F Zesmin. Lapraroscopic Assisted Vaginal Hysterectomy: A Case Control Comparative Study with Total Abdominal Hysterectomy., Department of Gynae \& Obstetrics, (SSMC \& MH), Dhaka, Faridpur Med. Coll J. 2013;8(2):59-62.

6. Lal Manju et al. Laproscopic assisted vaginal hysterectomy (LAVH)- truly an advance in gynaecological surgery. Department of Obstetrics \& Gynaecology, Swami Rama Himalayan University, Dehradun.,Int J Biol Med Res. 2014;5(3):4346-9.

7. Jaturasrivilai P. A Comparative study between Laproscopically Assisted Vaginal Hyaterectomy and Abdominal Hysterectomy. Department of Obstetrics and Gynaecology, Uttaradit Hospital, Uttaradit., J Med Assoc Thai. 2007;90(5):837-43.

8. Nisha K. Laparoscopic assisted Vaginal Hysterectomy (LAVH)- An effective alternative to conventional hysterectomy. Fortis escorts Hospital, Faridabad. J Obstet Gynecol India. 2010;60(5):42935 .

9. Kongawattanakul K. Comparison of laparoscopically assisted vaginal randomized controlled trial. Department of Obstetrics and Gynaecology, Faculty of Medicine, Khon Kaen University, Thailand. 2010.
10. Consultant CO, Lingman G, Ottosen L. Three methods for hysterectomy: a randomised, prospective study of short term outcome. BJOG: An International J of Obstetr Gynaecol. 2000;107(11):1380-5.

11. Arbogast JD, Welch RA, Riza ED, Ricaurte EL, Pieper DR. Laparoscopically assisted vaginal hysterectomy appears to be an alternative to total abdominal hysterectomy. Journal of laparoendoscopic surgery. 1994;4(3):185-90.

12. Sutasanasuang S. Laparoscopic hysterectomy versus total abdominal hysterectomy: a retrospective comparative study. J Medic Association of Thailand. 2011;94(1):8-16.

13. Jyotsana. Clinical Trial Of Laparoscopically Assisted Vaginal Hysterectomy Versus Total Abdominal Hysterectomy. Department OF Obstetrics and Gynaecology, SMGS Hospital and Government Medical College, Jammu, India. Jk Science. 2006; 8(2):97-100.

14. Nambiar KPM. LAVH or TAH- choosing it wise and making it safe. Department of Obstetrics and Gynaecology, Kastuba Medical College, Manipal University,Mangalore, India. Int J Reprod Contracept Obstet Gynecol. 2016;5(3):659-62.

Cite this article as: Sravanthi $\mathrm{P}$, Shivani D, Gunturu NJ. A comparative study of laparoscopic assisted vaginal hysterectomy versus total abdominal hysterectomy in benign gynaecological conditions. Int J Reprod Contracept Obstet Gynecol 2021;10:1540-4. 